\title{
Perspectives into What Will Happen After the End of COVID-19 Pandemic
}

\section{Dawood AA* \\ Department of Anatomy, College of Medicine, University of Mosul, Iraq}

*Corresponding author: Ali Adel Dawood, Department of Anatomy, College of Medicine, University of Mosul, Iraq, ORICD: 0000-0001-8988-5957; Email: aad@uomosul.edu.iq

\section{Review Article}

Volume 6 Issue 4

Received Date: October 18, 2021

Published Date: November 29, 2021

DOI: $10.23880 /$ oajmb-16000206

\section{Abstract}

History has proven that there are pandemics and there is little distinction between them in COVID-19. Earlier this year, investigators predicted the inevitability of third and fourth surge which could be greater than the previous. The statistics doubled. In the battle against the pandemic, even countries that played templates have been knocked down. We learned from the pandemic that: Developed nations should send medical teams to underdeveloped areas. It should close down social media websites that encourage users who receive disinformation to punish them. Nations should focus more on public education and awareness programs. Conserve biodiversity at all costs for all countries. Fatal virus experiments should be monitored and performed under stricter.

Keywords: COVID-19; Pandemic; Reserve; Nations

\section{Introduction}

Everything's going to end up going down. The constraints, the lockouts, the social isolation, the mask wear and the COVID-19 pandemic. Maybe not soon, but one day. History has proven that there are pandemics and there is little distinction between them in COVID-19. One day imagine hearing the title "The Last COVID-19 Patient Has Been Discharged from the Hospital" or "Officially Over, the COVID-19 Pandemic". Ultimately, COVID-19 is deleted and this uncomfortable chapter in our lives is finished, but what is left of it? Will the pandemic have taught us great lessons? Or are we going to reiterate the same errors and clear the way for another? Earlier this year, investigators predicted the inevitability of third and fourth surge which could be greater than the previous. Yet several people have denied this and pointed to it as "fake news," the easiest excuse in the book. It was the height of the first wave in March and April when I recall reading the regular number of deaths of COVID-19. Up to 6,000 people died a day. Now? Well? Up to 12,000 people die every day. The statistics doubled. In the battle against the pandemic, even countries that played templates have been knocked down. Can you imagine? Can you imagine? We learnt to deal with 12,000 deaths a day! [1,2].

A number of epidemiologists became the basis of the second wave forecast. Most of these being the pandemic of Spain's 1918 influenza, killing up to 50 million people. It wasn't until after the Spanish pandemic that people assumed a second wave began. It was deadly! It was fatal! The pandemic trend is now replicated. And what happened a hundred years ago was probably going to happen this time. Signs were present. We were told that and we denied it. At the moment, thousands of lives are the price for our stupidity. The third COVID-19 epidemic may have been stopped by a Spanish grippe pandemic lesson or two [3].

The people have always ignored humanity's best lessons and so we repeat our mistakes. It is highly doubtful that the insights from the COVID-19 pandemic are kept. It's not 100 years before I launch this time that I am sure that another pandemic will follow. However, we shall prevent it from 


\section{Open Access Journal of Microbiology \& Biotechnology}

happening as we take serious measures and learn from the COVID 19 pandemic. These are some of the things I guess I'll see at the completion of COVID-19:

1. If notified of a new condition, every country in the world should be asked to investigate every potential illness and report it with complete transparency. Countries that play down or bypass responsibility to defend their own interests should be sanctioned with the most serious sanctions [4].

2. Developed nations should send medical teams to underdeveloped areas to maintain track of possible diseases. It's much cheaper than a pandemic and will destroy the world's economy. Not just because pandemics occur rarely, it doesn't mean that it won't happen. This medical team should remain and continue to detect potential risks in these countries. These medical teams are to be supported and collaborated by each country.

3. Dissemination of knowledge begins to track the occurrence of any pandemic. So far, nearly 1, 6 million people died of a COVID-19 disinformation that was of great significance. Unfortunately, others did not follow the required preventive measures as they were not told. It should close down social media websites that encourage users who receive disinformation to punish them [5].

4. The number 3 can be avoided if correct instructions are present. Nations, not only in pandemics, should focus more on public education and awareness programs. Quality education means that people now understand the risks and the seriousness of their problems. This helps them to select well-trained and consistent.

5. More investments are research, creativity and growth. This is our best hope because soon after it begins we will end pandemics. Science investment makes analyzing and forecasting potential risks easier, quicker and more reliable. Advanced technology helps them to create new diagnoses and drugs to deter possible pandemics until record rates are higher [6].

6. Conserve biodiversity at all costs. When pandemics are introduced, erosion, climate change and environmental problems are increasingly apparent. The absence of ecosystems allows species to travel to where human beings reside, leading to new meetings between humans and animals, who may bring diseases. Inside the ice caps, no mention is made of thousands of antiquated virus organisms. Everyone is scientifically new. These viruses are released and new pandemics emerge as ice caps start to plummet.

7. Render dealing with deadly enigmatic viruses even more complicated. Fatal virus experiments should be monitored and performed under more strict, up-todate rules and guides without any existing therapy. Both pollutants in the laboratory are thus properly preserved. Any university or facility which defies these laws and

\author{
standards should be discontinued [7].
}

The pandemic of COVID-19 is not over yet, but our lessons are already widespread. I hope we retain this as soon as it is done in our history and memory books. The pandemic loop will continue until we take advantage of these interactions.

\section{Conclusions}

These are some of the things you guess and you see at the completion of COVID-19: Every country in the world should be asked to investigate every potential illness and report it with complete transparency. Dissemination of knowledge begins to track the occurrence of any pandemic. Nations should focus more on public education and awareness programs. The pandemic of COVID-19 is not over yet, but our lessons are already widespread. The pandemic loop will continue until we take advantage of these interactions.

\section{References}

1. Dawood AA (2020) Should we worry that the COVID-19 could be transmitted with the semen? As J Pharm Res 10(4): 319-320.

2. Dawood AA, Altobje MA (2020) Precautionary measures are taken by countries to reduce the transmission of the COVID-19. AJAMS 2(2): 29-32.

3. Dawood AA, Altobje MA (2020) Inhibition of N-linked Glycosylation by Tunicamycin May Contribute to The Treatment of SARS-CoV-2. Microbiol Path 149:104586.

4. Dawood A, Alnori HAM (2020) Tunicamycin Anticancer Drug May Reliable to Treat Coronavirus Disease-19. OAMJMS 8(T1): 129-133.

5. Dawood AA (2020) Mutated COVID-19 May Foretell a Great Risk for Mankind in The Future. N Mic N Inf 35: 100673.

6. Dawood AA,Altobje MA, Alnori HAM (2021) Compatibility of the Ligand Binding Sites in the Spike Glycoprotein of COVID-19 with those in the Aminopeptidase and the Caveolins 1, 2 Proteins. Res J Pharm Tech 14(9): 47604766.

7. Dawood AA, Altobje MA, Alrassam ZT (2021) Molecular Docking of SARS-CoV-2 Nucleocapsid Protein with Angiotensin-Converting Enzyme II. Mikrobio Zhu 83(2): 82-92. 